\title{
Within-subject variability of human semen in regard to sperm count, volume, total number of spermatozoa and length of abstinence
}

\author{
D. Schwartz, A. Laplanche, P. Jouannet* and G. David* \\ Unité de Recherches Statistiques de l'Institut National de la Santé et de la Recherche Médicale \\ (INSERM), 94800 Villejuif, France, and *Laboratoire d'Histo-Embryologie de l'Hôpital de \\ Bicêtre, 94270 Kremlin-Bicêtre, France
}

\begin{abstract}
Summary. The within-subject variability of the semen sperm count (n), volume (v) and the total number of spermatozoa $(\mathrm{N})$ was studied on 220 ejaculates from 36 normal subjects after an abstinence of 7 days or less. For each of the three variables, the within-subject standard deviation , $\sigma$, was practically proportional to the mean, $\mu$; the common value of the coefficient of variation $\sigma / \mu$ for all subjects was very high: 0.39 for $\mathrm{n}, 0.28$ for $\mathrm{v}$ and 0.55 for $\mathrm{N}$. The $95 \%$ confidence intervals based on a single ejaculate were asymmetrical and very large, the lower and upper limits being respectively $0.5 \times \mathrm{n}$ and $2.3 \times \mathrm{n} ; 0.7 \times \mathrm{v}$ and $1.8 \times \mathrm{v} ; 0.4 \times \mathrm{N}$ and $2.9 \times \mathrm{N}$. The three semen characteristics for a given subject were highly correlated with the length of abstinence: for an increase in abstinence of 1 day there were mean increments of $13 \times 10^{6} / \mathrm{ml}$ for $\mathrm{n}, 0.4 \mathrm{ml}$ for $\mathrm{v}$, and $87 \times 10^{6}$ for $\mathrm{N}$.
\end{abstract}

\section{Introduction}

Quantitative studies have already been made to investigate the great variability which exists for various semen characteristics in different ejaculates from the same individual (Hotchkiss, 1941; MacLeod \& Gold, 1956; Freund, 1962; Read \& Schnieden, 1978), as well as the influence of the length of abstinence (MacLeod \& Gold, 1952, 1953; Freund, 1962; Van Duijn \& Freund, 1971). However, the statistical analysis has often been limited and in no study are the results presented in such a way that direct comparisons can be made. Furthermore, the subjects of such studies have been either men consulting for sterility or volunteers with a high weekly ejaculation frequency.

The purpose of the present study was to evaluate within-subject variability for semen sperm count, volume and total number of spermatozoa as well as the effect of abstinence in normal subjects who maintained an approximately normal ejaculation frequency. The methods of statistical analysis used will permit direct comparisons with other studies.

\section{Materials and Methods}

\section{Patients}

The study was carried out at the sperm bank of Bicêtre Hospital near Paris with men who had requested cryopreservation of semen before undergoing vasectomy and had submitted several ejaculates for this purpose. No special instructions were given regarding sexual activity between visits to the sperm bank but a 3-day abstinence before each visit was advised. For this study, ejaculates preceded by an abstinence of over 7 days were excluded. All men seen in 
consultation between 1 January 1974 and 31 December 1976 who provided at least 5 ejaculates with a mean sperm count between 20 and $200 \times 10^{6} / \mathrm{ml}$ were included in the study. This resulted in a population of 36 men who provided a total of 220 ejaculates with the following distribution:

$\begin{array}{lrrrrr}\text { Number of ejaculates } & 5 & 6 & 7 & 8 & 9 \\ \text { Number of subjects } & 17 & 5 & 9 & 3 & 2\end{array}$

The length of abstinence was found to vary considerably for most subjects, 25 (70\%) reporting at least 3 different abstinence periods.

All subjects were fertile (having at least 1 child) and they had a mean ( \pm s.d.) age of $34.4 \pm$ $5 \cdot 3$ years.

\section{Techniques}

All semen samples were collected at the sperm bank by masturbation. The sperm count (n) and volume (v) were determined for each, the total number of spermatozoa being calculated as $\mathrm{N}=$ nv. The sperm count was carried out by first diluting the semen to $1: 20$ with a $1 \%$ Ringer's formol solution and then placing a portion into the 2 chambers of a haemocytometer (Thoma cell), each $0.1 \mathrm{~mm}^{3}$ in volume. A minimum of 400 spermatozoa was counted for each sample. Counting was carried out by the same person throughout the study period. Under these conditions, measurement errors according to Freund \& Carol (1964) are principally due to semen sampling error resulting in a coefficient of variation $<5 \%$. The volume was measured with a pipette to the nearest $0.1 \mathrm{ml}$.

\section{Statistical analysis}

The statistical techniques utilized have been described by Snedecor \& Cochran (1967). For the comparison of variances, distributions were compared to the $\chi^{2}$ probability density. When variances were not found to differ significantly, their weighted mean value was calculated. For the study of regressions, correlation coefficients and slopes were calculated for each subject and a weighted mean determined. For the confidence intervals, the calculation was made by using log $y(y=\mathrm{n}, \mathrm{v}$ or $\mathrm{N})$ since the variances of $\log y$ were found to be practically the same for all subjects (see 'Results'). Because there was not a normal within-subject distribution of $\log y$, it was necessary to use the observed distribution of $\log y$. All the above calculations have been detailed by Laplanche (1978).

\section{Results}

\section{Mean values}

The mean values calculated for the 220 semen samples were: $\mathrm{n}=99 \times 10^{6} / \mathrm{ml}, \mathrm{v}=4.1 \mathrm{ml}$ and $n v(\mathrm{~N})=401 \times 10^{6}$.

\section{Within-subject variability}

For each of the 3 characteristics studied, the within-subject standard deviation $(\sigma)$, upon inspection, appeared to increase proportionally with the mean $(\mu)$ as is shown for $n$ in Text-fig. 1 (for $\mathrm{v}$ and $\mathrm{N}$ the patterns were similar). In order to test the hypothesis $\sigma / \mu$ equals a constant, the within-subject variances of $\log y\left(y=\mathrm{n}, \mathrm{v}\right.$ or $\mathrm{N}$ ) which are equal to $\sigma^{2} / \mu^{2}$ (Lellouch \& Lazar, 1974) were compared among the 36 subjects. As no significant difference was found, the hypothesis was retained. The common value for all subjects of the coefficient of variation $(\sigma / \mu)$ was 0.39 for $\mathrm{n}, 0.28$ for $\mathrm{v}$ and 0.55 for $\mathrm{N}$. 


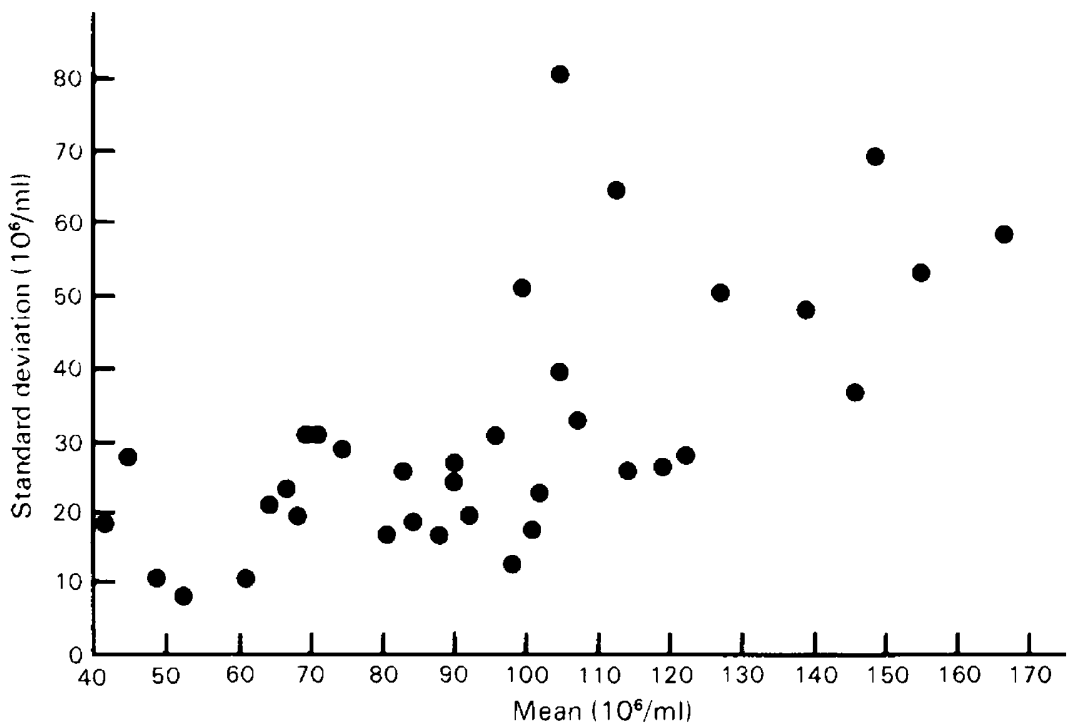

Text-fig. 1. Relationship between the within-subject standard deviation and the individual mean for the sperm count $(n)$ in men.

For each of the 3 characteristics, the $95 \%$ confidence intervals for a given subject based on a single ejaculate $\left(n_{e}, v_{e}, N_{e}\right)$ were obtained. The lower and upper limits, respectively, were found to be: $0.5 \times \mathrm{n}_{\mathrm{e}}$ and $2.3 \times \mathrm{n}_{\mathrm{e}} ; 0.7 \times \mathrm{v}_{\mathrm{e}}$ and $1.8 \times \mathrm{v}_{\mathrm{e}} ; 0.4 \times \mathrm{N}_{\mathrm{e}}$ and $2.9 \times \mathrm{N}_{\mathrm{e}}$.

\section{Semen characteristics and length of abstinence}

The relationship between each variable $(n, v, N)$ and the length of abstinence for all 220 specimens appeared to be linear, at least between 1 and 5 days (Text-fig. 2).
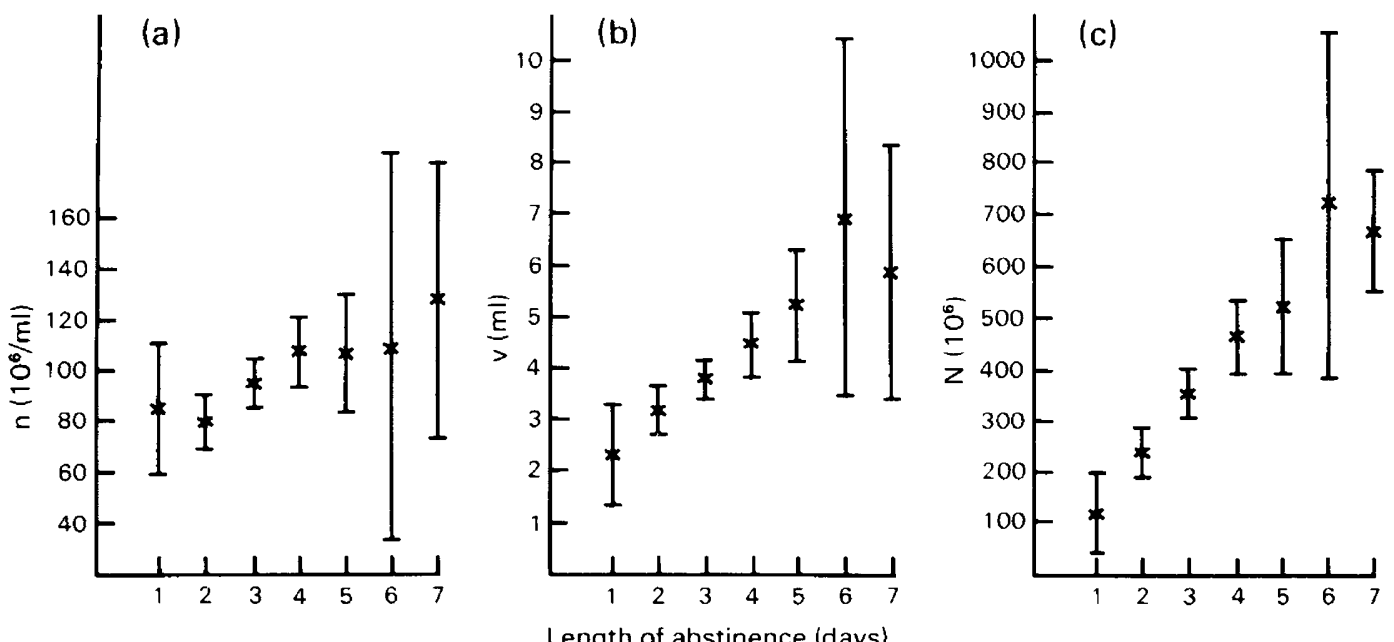

Text-fig. 2. Regression of (a) sperm count, $n$, (b) volume, v, and (c) total number of spermatozoa, $\mathbf{N}$, on length of abstinence before ejaculation by men. The values represent the mean \pm 2 s.e. for $8,32,92,62,20,2$ and 4 ejaculates after abstinence for $1,2,3,4,5,6$ and 7 days respectively. 
The calculations were made on a within-subject basis. The within-subject correlation coefficients $(r)$ were highly significant: 0.39 for $\mathrm{n}\left(P<10^{-5}\right), 0.47$ for $\mathrm{v}\left(P<10^{-6}\right)$ and 0.54 for $\mathrm{N}\left(P<10^{-9}\right)$. There were no departures from linearity for each subject for the 3 variables. The weighted mean value of individual slopes was such that each additional day of abstinence resulted in increases of $\mathrm{n}, \mathrm{v}$ and $\mathrm{N}$ equal to $13 \times 10^{6} / \mathrm{ml}, 0.4 \mathrm{ml}$ and $87 \times 10^{6}$ respectively. In order to determine if there were a relationship between individual slopes and means, correlation coefficients among the 36 subjects were calculated. For $n, v$ and $N$ the values were $0.21,0.22$ and 0.32 respectively. Even though only the last was significant, the results suggest that the slope and the mean are related in a positive sense.

\section{Discussion}

For the 3 semen characteristics studied, the within-subject standard deviation varies proportionally with the mean value and thus the within-subject coefficient of variation is constant. Four authors have provided sufficiently detailed data to permit us to calculate the coefficients of variation for their studies and a comparison of these with our own values reveals very good agreement (Table 1), even for the study by Read \& Schnieden (1978) which was carried out with oligozoospermic and astheno-zoospermic subjects. The coefficients of variation for all studies are very high, being of the order of $40 \%$ for $n, 30 \%$ for $v$ and $55 \%$ for $N$.

Table 1. Within-subject coefficients of variation in different studies of human semen

\begin{tabular}{|c|c|c|c|c|c|}
\hline & $\begin{array}{l}\text { Hotchkiss } \\
\quad(1941)\end{array}$ & $\begin{array}{l}\text { MacLeod \& Gold } \\
\quad(1956)\end{array}$ & $\begin{array}{l}\text { Freund } \\
(1962)\end{array}$ & $\begin{array}{c}\text { Read \& Schnieden* } \\
(1978)\end{array}$ & $\begin{array}{l}\text { Present } \\
\text { study }\end{array}$ \\
\hline No. of subjects & 23 & 12 & 12 & 16 & 36 \\
\hline No. of ejaculates & 640 & 919 & 140 & 118 & 220 \\
\hline $\mathrm{n}$ & 0.36 & 0.40 & 0.41 & 0.47 & 0.39 \\
\hline $\mathrm{v}$ & 0.24 & - & 0.29 & - & 0.28 \\
\hline $\mathbf{N}$ & 0.42 & - & 0.75 & 0.53 & 0.55 \\
\hline
\end{tabular}

* Oligozoospermic or astheno-zoospermic subjects.

In view of this high within-subject variability, what information can be obtained from a single ejaculate? The present study has approached this question by determining the $95 \%$ confidence intervals for mean values of $\mathrm{n}, \mathrm{v}$ and $\mathrm{N}$ which were wide and asymmetrical. For example, if a single sperm count of $100 \times 10^{6} / \mathrm{ml}$ were determined, the mean value for the subject could lie anywhere between 50 and $230 \times 10^{6} / \mathrm{ml}$. Only a very small part of this variability can be attributed to measurement errors which were minimal as explained in 'Materials and Methods'. Thus, the variability must be essentially biological.

Certainly one influential factor is the period of abstinence. In our sample all 3 semen characteristics for a given subject are highly correlated with this period, the relationship being practically linear. In other studies the importance of the length of abstinence has been only mentioned (Belding \& Boston, 1934; Hotchkiss, 1941; Hammen, 1944; MacLeod \& Heim, 1945; Lampe \& Masters, 1956; Zimmermann, Maude \& Moldawer, 1965), described graphically (Raboch, 1957; Murphy, 1962) or subjected to more or less elaborate statistical tests (MacLeod \& Gold, 1952, 1953; Freund, 1962; Van Duijn \& Freund, 1971). In these studies, the slopes were not evaluated but it was possible to calculate one slope for each characteristic from the data of 2 studies: the increments per day of abstinence were $12 \times 10^{6} / \mathrm{ml}$ for $\mathrm{n}$ and $60 \times 10^{6}$ for $\mathrm{N}$ in the study of MacLeod \& Gold (1952) and $0.3 \mathrm{ml}$ for $\mathrm{v}$ in the study of Raboch (1957). These values agree well with the results of the present study which are respectively $13 \times 10^{6} / \mathrm{ml}$, 
$87 \times 10^{6}$ and $0.4 \mathrm{ml}$. These increments are very large when compared to the respective mean value of each characteristic.

The part of within-subject variability attributable to length of abstinence $\left(r^{2}\right)$ is 15,22 and $29 \%$ for $n, v$ and $N$ respectively. Therefore, a very large part of the within-subject variability in semen characteristics remains unexplained and justifies further investigation. However, the results of this study indicate that it is no longer possible to ignore, from the clinical or the research point of view, the high variability which exists for semen characteristics or the relationship of these characteristics to length of abstinence.

\section{References}

Belding, D.L. \& Boston, M.D. (1934) Fertility in the male. II. Technic of the spermatozoa count. Am. J. Obstet. Gynec. 27, 25-31.

Freund, M. (1962) Interrelationships among the characteristics of human semen and factors affecting semen-specimen quality. J. Reprod. Fert. 4, 19431959.

Freund, M. \& Carol, B. (1964) Factors affecting haemocytometer counts of sperm concentration in human semen. J. Reprod. Fert. 8, 149-155.

Hammen, R. (1944) Studies in impaired fertility in man. Thèse de Médecine, $n^{\circ} 26$. E. Munsgaard, Edit. Copenhagen.

Hotchkiss, R.S. (1941) Factors in stability and variability of semen specimens: observations on 640 successive samples from 23 men. J. Urol. 45, 875888 .

Lampe, E.H. \& Masters, W.H. (1956) Problems of male fertility. II. Effects of frequent ejaculation. Fert. Steril. 7, 123-127.

Laplanche, A. (1978) Variabilité intra-individuelle du sperme humain pour la numération, le volume et le nombre total de spermatozoïdes. Rôle du délai de continence. Mèmoire D.E.R.B.H., Unitè de Recherches Statistiques INSERM, 94800 Villejuif, France.

Lellouch, J. \& Lazar, P. (1974) Méthodes Statistiques en Expérimentation Biologique. Flammarion Edit., Paris.

MacLeod, J. \& Gold, R.Z. (1952) The male factor in fertility and infertility. V. Effect of continence on semen quality. Fert. Steril. 3, 297-315.
MacLeod, J. \& Gold, R.Z. (1953) The male factor in fertility and infertility. VII. Semen quality in relation to age and sexual activity. Fert. Steril. 4, 194-209.

MacLeod, J. \& Gold, R.Z. (1953) The male factor in fertility and infertility. VIII. A study of variation in semen quality. Fert. Steril. 7, 387-410.

MacLeod, J. \& Heim, L. M. (1945) Characteristics and variations in semen specimens in 100 normal young men. J. Urol. 54, 474-482.

Murphy, D.P. (1962) The effect of ejaculation upon the sperm count: report of a case. J. Urol. 88, 431-432.

Raboch, J. (1957) Some factors influencing the secretory activity of sexual accessory glands in men. Fert. Steril. 8, 227-232.

Read, M. D. \& Schnieden, H. (1978) Variations in sperm count in oligozoospermic or asthenozoospermic patients. Andrologia, 10, 52-55.

Snedecor, G.W. \& Cochran, W.G. (1967) Statistical Methods. Iowa State University Press, Ames, Iowa.

Van Duijn, C. \& Freund, M. (1971) The relationship between some seminal characteristics and ejaculation frequency in the human male. Eur. J. Obstet. Gynec. 5, 167-174.

Zimmerman, S.J., Maude, M.B. \& Moldawer, M. (1965) Frequent ejaculation and total sperm count motility, and form in humans. Fert. Steril. 16, 342-345.

Received 9 February 1979 